\title{
Relationship between silicosis and rheumatoid arthritis
}

\author{
GK SLUIS-CREMER, PA HESSEL, E HNIZDO, AR CHURCHILL \\ From the Epidemiology Research Unit, Johannesburg, South Africa
}

ABSTRACT The relationship between rheumatoid arthritis and silicosis was studied by means of a case-control study in South African goldminers. One hundred and fifty seven miners with rheumatoid arthritis classified as "definite" (91) or "probable" (66) were individually matched by year of birth with miners who had no evidence of rheumatoid arthritis. Unmatched analysis of the case-control status for "probable" and "definite" cases yielded an odds ratio of $2 \cdot 84(\mathrm{p}=0.0001)$. Separate analyses yielded an odds ratio of $3.79(\mathrm{p}=0.0006)$ for "definite" cases, a non-significant odds ratio for "probable" cases, and an odds ratio of $5.00(\mathrm{p}=0.0003)$ for the presence of rheumatoid factor. These results could not be explained on the basis of cumulative dust exposure or intensity of exposure. The rate of progression of silicosis in both the "definite" and the "probable" groups was greater than for the control patients with silicosis, as was the probability of silicosis presenting at the start with larger nodules (type $r$ ).

The radiological and histological features of silicosis are sometimes modified in a characteristic manner in miners with rheumatoid arthritis ${ }^{1}$-a phenomenon seen also in coalminers' pneumoconiosis. ${ }^{23}$ The question of whether silicosis occurs more readily in individuals with rheumatoid arthritis exposed to silica has not, however, been addressed.

Silicosis occurs in South African gold miners, who may be exposed to dust containing high levels of free silica. The main objective of this study was to determine whether silicosis was present more often in miners with rheumatoid arthritis than in miners without, and to determine whether any differences found in the prevalence of silicosis could be explained by differences in the amount or intensity of exposure to silica dust. Miners with silicosis and rheumatoid arthritis were compared with those without rheumatoid arthritis to establish whether the rate of progression and other features of silicosis were different under conditions of equal exposure to silica dust. Index subjects with silicosis who were seropositive for rheumatoid factor were compared with the control subjects with silicosis to determine whether the presence of rheumatoid factor was relevant to the progression of silicosis.

Address for reprint requests: Dr GK Sluis-Cremer, Epidemiology Research Unit, PO Box 4584, Johannesburg, South Africa 2000.

Accepted 7 February 1986

\section{Methods}

Case-control methods were used. Workers with rheumatoid arthritis were identified from all white gold miners attending the Medical Bureau for Occupational Diseases for benefit examinations from 1967 to 1979 . The gold mines contain dust with more than $30 \%$ free silica and there have been no major changes in dust concentrations since the late 1930s. Benefit examinations are performed to assess whether a miner is suffering from pneumoconiosis or other compensatable diseases or whether change in an existing compensatable disease means that he is eligible for additional compensation. Such examinations, which may be repeated annually, comprise a full examination by a specialist physician, chest radiography, and lung function tests, and other tests (including blood tests) as necessary. These examinations usually continue after cessation of mining exposure, as men may benefit financially if there is clinical deterioration.

The diagnosis of rheumatoid arthritis was based on the clinical features described in the physicians' written reports and in most cases on several successive annual reports. In all cases arthritis had been present for at least one year. Only cases considered definite or probable according to the American Rheumatism Society criteria ${ }^{4}$ were accepted. One hundred and fifty seven cases were identified, of which 91 were classified as definite and 66 as probable rheumatoid arthritis. In 
100 of the 157 cases serological tests for rheumatoid factor had been performed, of which 70 yielded a positive result $(80 \%$ of the 66 definite cases tested and $56 \%$ of the 30 probable cases).

Recording clinical features to allow a classification of "definite" rheumatoid arthritis had not been carried out systematically in these cases, since that was not the purpose of the examination. As a result an unknown number of "definite" cases are likely to have been classified as "probable." The year of onset of rheumatoid arthritis was obtained from the clinical data recorded at the benefit examinations or the periodical examinations. Periodical examinations are annual and obligatory for all miners while working in dusty occupations, but are not carried out by specialists. Symptoms and signs relevant to joint diseases are recorded routinely.

The controls were randomly selected from white men who attended the Medical Bureau for Occupational Diseases for benefit examinations from April 1970 to the end of March 1971. One control was individually matched with each case by year of birth ( \pm 1 year). Controls who had any suggestion of rheumatoid arthritis were excluded.

For each subject the most recent chest radiograph was read on a four point scale of profusion corresponding to the major categories of the International Labour Office 1971 classification for silicosis by a single reader (GKS-C) without the knowledge of whether the film was that of a case or a control. The year of first appearance for each major category of profusion (that is, 1, 2, 3) was recorded when applicable and also, when relevant, the year when progressive massive fibrosis was first seen. Progression of silicosis was calculated for each subject who had at least one year between the first film showing signs of silicosis and the most recent film. Progression was calculated in major categories per year. Progressive massive fibrosis was analysed separately. The number of shifts worked in different occupations and the dust levels of these occupations were available for the gold miners. Some gold miners had been exposed to silica in mines other than gold mines but this was always a minor fraction of their total mining experience.

Case-control differences in dust exposure were calculated in terms of cumulative silica dust exposure, intensity of exposure, and length of exposure. Cumulative dust exposure was calculated up to the date of onset of silicosis for cases and controls, and up to the onset of rheumatoid arthritis for cases and for the same time for each matched control. It was calculated by multiplying the number of shifts worked in a given occupation by a weighting factor proportional to the dust level of that occupation ${ }^{5}-12$ for underground high dust levels; six for underground moderate dust levels; three for underground low dust levels and all surface dusty occupations; two for occupations in mines containing silica other than gold mines (that is, copper, amphibole asbestos, etc); and one for service in mines containing a very little silica, dusty factories, and quarries. Weighting factors for non-gold mining service were based on available information on silica content of the dusts, mining techniques, and work processes. While the weighting factors for these exposures represent a greater degree of approximation than for the gold mines, very little of the service recorded for the study subjects was performed outside the large gold mines. Intensity of dust exposure was computed by summing the dust weighting factors for the various occupations multiplied by the number of shifts spent in those occupations and dividing by the total number of shifts worked (that is, a weighted average). The length of exposure was calculated by summing all the shifts.

Unmatched analyses were performed for all 157 cases. Separate analyses were carried out for cases classified as "definite" and as "probable" and for cases according to whether they were positive or negative in the serological test for rheumatoid factor or had had no test performed. The risk of having silicosis in the presence of rheumatoid arthritis was estimated from the odds ratio with $95 \%$ confidence intervals determined from the formula of Liddell. ${ }^{6}$ The cross classified data were evaluated with the $\chi^{2}$ test and the odds ratio, and the case-control differences in dust exposure variables with the Wilcoxon two sample test. Since distribution of the progression of silicosis was found to be exponential, the Savage nonparametric test ${ }^{7}$ was applied to assess differences.

\section{Results}

Five index subjects had radiological evidence of interstitial pulmonary fibrosis, two of whom also had silicosis. The mean age of onset of silicosis was 52 years for the index subjects with rheumatoid arthritis and 50 years for the control subjects. The subjects with silicosis with and without rheumatoid arthritis had started their dust exposure at mean ages of 21.7 and 21.8 years respectively. The mean ages for the case and control subjects with silicosis for the last exposure to silica were 52.3 and 54.2 years, and for the last chest radiograph 59.4 and 60.4 years.

The unmatched comparison of the 157 cases and their controls by presence or absence of silicosis (table 1) yielded an odds ratio of $2 \cdot 84(p=0.0001)$. For the 91 "definite" and 66 "probable" cases the odds ratios were $3.79(p=0.0006)$ and $1.94(p=0.131)$.

Table 2 shows the odds ratios for the three groups according to whether subjects were positive or negative for the rheumatoid factor or not tested. The highest odds ratio was seen with the seropositive 
Table 1 Comparison of cases (subjects with definite and probable rheumatoid arthritis) and matched controls for presence of silicosis $(S)$

\begin{tabular}{|c|c|c|c|c|c|c|}
\hline & \multicolumn{2}{|c|}{ All cases } & \multirow{2}{*}{$\frac{\text { Definite }}{S+}$} & \multirow[b]{2}{*}{$S-$} & \multicolumn{2}{|c|}{ Probable } \\
\hline & $\overline{S+}$ & $S-$ & & & $S+$ & $S-$ \\
\hline $\begin{array}{l}\text { Cases } \\
\text { Controls }\end{array}$ & $\begin{array}{l}46 \\
20\end{array}$ & $\begin{array}{l}111 \\
137\end{array}$ & $\begin{array}{l}29 \\
10\end{array}$ & $\begin{array}{l}62 \\
81\end{array}$ & $\begin{array}{l}17 \\
10\end{array}$ & $\begin{array}{l}49 \\
56\end{array}$ \\
\hline $\begin{array}{l}\text { Odds ratios } \\
95 \% \text { confidence intervals } \\
\chi^{2}(1) \\
\mathrm{p} \text { value }\end{array}$ & \multicolumn{2}{|c|}{$\begin{array}{l}2 \cdot 84 \\
12.97 \\
0.0001\end{array}$} & \multicolumn{2}{|c|}{$\begin{array}{l}11 \cdot 78^{1 \cdot 72-8.36} \\
0.0006\end{array}$} & \multicolumn{2}{|c|}{$0.81-4.63$} \\
\hline
\end{tabular}

Table 2 Comparison of cases and matched controls for presence of silicosis $(S)$ according to the presence of rheumatoid factor $(R F)$ in the cases

\begin{tabular}{|c|c|c|c|c|c|c|}
\hline & \multicolumn{2}{|c|}{$R F$ positive } & \multicolumn{2}{|c|}{$R F$ negative } & \multicolumn{2}{|c|}{ Not tested } \\
\hline & $S+$ & $S-$ & $S+$ & $S-$ & $S+$ & $S-$ \\
\hline $\begin{array}{l}\text { Cases } \\
\text { Controls }\end{array}$ & $\begin{array}{r}25 \\
7\end{array}$ & $\begin{array}{l}45 \\
63\end{array}$ & $\begin{array}{l}9 \\
7\end{array}$ & $\begin{array}{l}17 \\
19\end{array}$ & $\begin{array}{r}12 \\
6\end{array}$ & $\begin{array}{l}49 \\
55\end{array}$ \\
\hline $\begin{array}{l}\text { Odds ratios } \\
95 \% \text { confidence intervals } \\
\chi^{2}(1) \\
\mathrm{p} \text { value }\end{array}$ & \multicolumn{2}{|c|}{$\begin{array}{l}5 \cdot 00 \\
13 \cdot 13^{1.99-12 \cdot 56} \\
0.0003\end{array}$} & \multicolumn{2}{|c|}{$\begin{array}{ll}1.44 & \\
0.36 & 0.44-4.73\end{array}$} & \multicolumn{2}{|c|}{$2.250 .78-6.43$} \\
\hline
\end{tabular}

Table 3 Dust exposure up to the onset of silicosis for all controls with silicosis and for two subgroups of subjects with silicosis and rheumatoid arthritis $(R A)$

\begin{tabular}{|c|c|c|c|}
\hline & Definite $R A$ & Positive for $R F$ & Controls \\
\hline $\begin{array}{l}\text { Number } \\
\text { Cumulative dust exposure } \\
\text { Intensity } \\
\text { Total shifts }\end{array}$ & $\begin{array}{c}29 \\
35900 \\
5 \cdot 31^{*} \\
6893\end{array}$ & $\begin{array}{c}25 \\
36586 \\
5 \cdot 11 \dagger \\
7265\end{array}$ & $\begin{array}{c}20 \\
41063 \\
6 \cdot 81 \\
6125\end{array}$ \\
\hline
\end{tabular}

${ }^{*} \mathrm{p}=0.004$, comparison with controls.

$+\mathrm{p}=0.002$, comparison with controls.

$\mathrm{RF}$ - rheumatoid factor.

Table 4 Comparison between definite and probable cases of rheumatoid arthritis (RA) with silicosis and controls with silicosis

\begin{tabular}{|c|c|c|c|}
\hline & Definite $R A$ & Probable RA & Controls \\
\hline $\begin{array}{l}\text { Total No of subjects } \\
\text { No with silicosis } \\
\% \text { presenting with } \mathrm{r} \text { nodules } \\
\text { No with silicosis with } \geqslant 1 \text { y between onset of silicosis and last } \\
\text { radiograph } \\
\% \text { developing PMF } \\
\text { Progression score } \\
\text { Years from onset to highest profusion }\end{array}$ & $\begin{array}{l}91 \\
29 \\
24^{*} \\
25 \\
32 \\
0 \cdot 22 \\
6 \cdot 16\end{array}$ & $\begin{array}{l}66 \\
17 \\
29 * \\
16 \\
25 \\
0 \cdot 27+ \\
4 \cdot 38^{*}\end{array}$ & $\begin{array}{r}157 \\
20 \\
5 \\
19 \\
16 \\
0 \cdot 11 \\
8 \cdot 63 \\
\end{array}$ \\
\hline
\end{tabular}

${ }^{*} \mathrm{p}<0 \cdot 10$, comparison with controls.

$t \mathrm{p}=0.05$, comparison with controls.

PMF-Progressive massive fibrosis. 
Table 5 Comparison of rheumatoid factor ( $R F)$ positive and negative cases with silicosis and controls with silicosis

\begin{tabular}{|c|c|c|c|}
\hline & $R F+$ & $R F-$ & Controls \\
\hline $\begin{array}{l}\text { Total No of subjects } \\
\text { No with silicosis } \\
\% \text { presenting with } \mathrm{r} \text { nodules } \\
\text { No with silicosis with } \geqslant 1 \mathrm{y} \\
\text { to progress } \\
\% \text { developing PMF } \\
\text { Progression score } \\
\text { Years from onset to highest } \\
\text { profusion }\end{array}$ & $\begin{array}{l}70 \\
25 \\
36^{*} \\
22 \\
36 \\
0 \cdot 22 \dagger \\
4 \cdot 91 \dagger\end{array}$ & $\begin{array}{l}9 \\
22 \\
0.20 \dagger \\
6.11\end{array}$ & $\begin{array}{l}19 \\
16 \\
0 \cdot 11 \\
8.63\end{array}$ \\
\hline
\end{tabular}

In 61 cases serological tests were not done.

${ }^{*} \mathrm{p}<0.05$, comparison with controls.

tp $<0 \cdot 10$, comparison with controls

PMF-progressive massive fibrosis.

cases - that is, $5.00(p=0.0003)$; the ratio for the seronegative group was $1.44(\mathrm{p}=0.55)$, and the ratio for those not tested was $2 \cdot 25(\mathrm{p}=0 \cdot 13)$.

Although there was no significant difference in cumulative dust exposure or length of exposure in shifts up to the onset of silicosis in the two groups (table 3), the average intensity of dust exposure was significantly less for the cases than for the controls.

There was little difference between "definite" and "probable" cases in the percentage presenting with " $r$ " sized nodules, in the proportion developing progressive massive fibrosis, and in the progression score (table 4). All of these indices were significantly higher for both "definite" and "probable" cases than for controls, whereas the time from onset of silicosis to the highest profusion seen was less.

The seropositive subjects were significantly more likely to present with " $r$ " type nodules (table 5), to develop progressive massive fibrosis, and to have a higher progression score than the controls, while the time from onset to highest profusion was less.

\section{Discussion}

This study suggests that miners with rheumatoid arthritis when exposed to silica are more likely to develop silicosis than are miners without rheumatoid arthritis (table 1). When data on the definite and probable cases and the matched controls were analysed separately the excess of silicosis was largely accounted for by the "definite" cases. The "probable" group may have included cases that would have been "definite" if the clinical data had been more complete. The considerable difference in the odds ratios between the two groups suggests, however, that classification as "definite" and "probable" was appropriate. The "probable" group must presumably have included subjects who did not have rheumatoid arthritis.

In $80 \%$ of "definite" cases tested for rheumatoid factor the results were positive, compared with $56 \%$ among the "probable" cases. The proportion of miners with silicosis in the seropositive and seronegative groups did not, however, differ significantly $(\mathrm{p}=$ $0 \cdot 28$ ), so the finding of a higher odds ratio for the "definite" cases than for the "probable" cases is unlikely to have been entirely due to a higher proportion of seropositive cases among the "definite" cases. The "definite" rheumatoid arthritis and the seropositive groups overlap considerably, so it is impossible from these data to decide whether rheumatoid factor or another immunological aspect of rheumatoid arthritis is associated with the increased risk of silicosis.

The high odds ratios for the "definite" cases and for the rheumatoid factor positive cases could not be attributed to cumulative dust exposure or to the intensity of exposure, which were lower than in the controls, although the number of shifts was higher. The patients with arthritis are likely to have retired from high dust occupations, which are in general physically more arduous, because of their disability.

It has been shown previously that the quantity of silica deposited in the lungs is not the only factor in the causation and progression of silicosis. Pathogen free rats treated with silica or intratracheal tridymite developed mild, slowly progressing fibrosis ${ }^{8}$; whereas identically treated rats kept under normal laboratory conditions, where they are exposed to many pathogens, developed much more severe silicosis despite having similar amounts of silica in the lungs. ${ }^{9}$

It has been claimed that rheumatoid arthritis may occur with accelerated silicosis. ${ }^{10}$ In this study, however, there was no difference in cumulative dust exposure or in length or intensity of silica exposure up to onset of rheumatoid arthritis between cases and controls. Overmatching may have occurred, however, as both cases and controls were selected from men undergoing benefit examinations, who in general have had long exposures. If there is an association between exposure to silica dust and the development of rheumatoid arthritis it is unlikely to be a strong one.

Exposure to silica is, however, associated with some immunological phenomena, including an increased incidence of the autoimmune disease scleroderma, ${ }^{11}$ and possibly lupus erythematosus, ${ }^{12}$ and the production of rheumatoid factor in animals and man in the absence of rheumatoid arthritis. In animal experiments the evidence is conflicting. A rheumatoid like factor has been detected after both intravenous ${ }^{13}$ and intratracheal injection ${ }^{14}$ of silica, but negative results after intravenous and intraperitoneal administration have also been reported. ${ }^{15}$ Webster et al report the occurrence of rheumatoid factor in two out of four baboons exposed to silica. ${ }^{16}$ Rheumatoid factor was present more frequently in men with silicosis 
$(28 \%)$ in one study but only in sandblasters, who have very high intensity exposure. ${ }^{17}$

Whether workers with rheumatoid factor are more likely to develop silicosis when exposed to silica is at present unknown. Studies of 195 gold miners with 20-25 years' underground service and with no rheumatoid arthritis ${ }^{16}$ showed that $21 \%$ had a titre of $1 / 64$ or higher in the human erythrocyte agglutination test and $12 \%$ a titre of over $1 / 1280$ in the latex agglutination test. The results of the agglutination tests did not correlate with the development or progression of silicosis over the next six years. Parkes has suggested that circulating rheumatoid factor may be associated with "suddenly advancing silicosis" ${ }^{18}$ but the evidence at present is inconclusive.

Both rheumatoid arthritis and the ability to produce rheumatoid factors appears to be in part under genetic control. Rheumatoid arthritis has a strong association with the antigen HLA-Dr 4 in seropositive patients. ${ }^{19}$ The strong association between rheumatoid arthritis and silicosis may be due to the underlying immunogenetic features of rheumatoid arthritis.

Presentation of silicosis with " $r$ " nodules $(3-10 \mathrm{~mm}$ diameter) was more common in both "definite" and "probable" cases of rheumatoid arthritis than in the controls. A recent radiological-pathological correlation study in coalminers found that the presentation of " $r$ " nodules was sometimes associated with pathological features of Caplan's syndrome and with the "rheumatoid diathesis." 20 We considered whether our findings could be attributed to Caplan's syndrome. Of the 157 index subjects, 68 have died and the lungs have been obtained for examination. Silicosis was confirmed in 54 patients at the time. When the 40 cases for which histological material was still available were reviewed none showed all the features of rheumatoid pneumoconiosis, although some features were present in eight (B Goldstein, personal communication - to be reported separately). Some degree of silicosis was found, not unexpectedly, in some cases in which radiographs in life had been normal. It is most unlikely that the phenomena reported in this paper are due to Caplan's syndrome.

The rate of progression of silicosis was higher in both the "definite" and the "probable" rheumatoid arthritis groups than in the controls. There was also a trend for progressive massive fibrosis to occur more frequently in cases of rheumatoid arthritis despite the fact that the time between onset of silicosis to highest profusion was lower for both "definite" and "probable" cases than for controls. The "probable" cases had as high a progression score as the "definite" cases and presented as often with " $r$ " nodules, despite the fact that the association between rheumatoid arthritis and silicosis was not significant in this group. Possi- bly, although the definite and the probable cases include different "diseases," they have some immunological mechanisms in common, other than the production of rheumatoid factor, that affects the behaviour of silicosis.

Individuals with silicosis who are positive for rheumatoid factor are particularly liable to present with " $r$ " nodules. Progression scores were similar in the groups positive and negative for rheumatoid factor groups and both sets of scores were higher than in controls, again suggesting that immunological mechanisms not associated with rheumatoid factor may be operative. Patients with seronegative rheumatoid arthritis may have circulating immune complexes or hidden rheumatoid factor. ${ }^{21}$

This study indicates that rheumatoid arthritis that can be classified as "definite" is associated with a considerably increased risk of silicosis not explicable by any measure of silica exposure. The same applies to seropositive cases of arthritis. Both "definite" and "probable" rheumatoid arthritis show faster progression of silicosis and a trend towards a higher risk of progressive massive fibrosis.

\section{References}

1 Chatgdakis CF, Theron CP. Rheumatoid pneumoconiosis (Caplan's syndrome). Arch Environ Health 1961;2:397-408.

2 Caplan A. Certain unusual radiological appearances in the chests of coal miners suffering from rheumatoid arthritis. Thorax 1953;8:29-37.

3 Gough J, Rivers D, Seal RMF. Pathological studies of modified pneumoconiosis in coal miners with rheumatoid arthritis (Caplan's syndrome). Thorax 1955; 10:9-18.

4 Ropes MW, Bennett GA, Cobb S, Jocox R, Jessar RA. Revision of diagnostic criteria for rheumatoid arthritis. Bull Rheum Dis 1958;9:175-6.

5 Beadle DG, Harris E, Sluis-Cremer GK. The relationship between the amount of dust breathed and the incidence of silicosis. In: Shapiro HA, ed. Pneumoconiosis: proceedings of the international conference, Johannesburg, 1969. London: Oxford University Press, 1970;473-7.

6 Liddell FDK. Simplified exact analysis of case-referent studies: matched pairs, dichotomous exposure. J Epidemoil Commun Health 1983;37:82-4.

7 Hajek JA. Course in non-parametric statistics: San Francisco: Holden-Day, 1969:83.

8 Heppelston AG. Atypical reaction to inhaled silica. Nature 1967;213:199.

9 Chiappino AG, Vigliani EC. Role of infective, immunological, and chronic irritative factors in the development of silicosis. Br J Ind Med 1982;39:253-8.

10 Ziskind M, Jones RN, Weill H. Silicosis. Am Rev Respir Dis 1976;113:643-65.

11 Erasmus LD. Scleroderma in gold miners on the Witwatersrand with particular reference to pulmonary 
manifestation. S Afr J Lab Clin Med 1957;3:209-31.

12 Bailey WC, Brown M, Buechner HA, Weill H, Ichinose $\mathrm{H}$, Ziskind M. Silico-mycobacterial disease in sand blasters. Am Rev Respir Dis 1974;110:115-25.

13 Vigliani EC, Pernis B. Immunological aspects of silicosis. Adv Tuberc Res 1963;12:230-72.

14 Esber HJ, Burrell R. An immunologic study of experimental silicosis. Environ Res 1967;1:171-7.

15 Schroeder W, Franklin EC, McEwen C. Rheumatoid factors in patients with silicosis with round nodular fibrosis of the lung in the absence of rheumatoid arthritis. Arth Rheum 1962;5:10-8.

16 Webster I, Miller K, Werntraub Z, et al. Pathogenesis of silicosis. In: National Centre for Occupational Health. Annual report 1979. Johannesburg: Department of
Health, Republic of South Africa: 10.

17 Doll NJ, Stankus RP, Hughes J, et al. Immune complexes and autoantibodies in silicosis. $J$ Allergy Clin Immunol 1981;68:281-5.

18 Parkes WR. Occupational lung disorders. 2nd ed. London: Butterworths, 1982:151.

19 Dobloug JH, Forre O, Chattopadhyay C, Natvig JB. Evidence for altered immunoregulation in rheumatoid arthritis. Semin Immunopathol 1981;4:125-31.

20 Ruckley VA, Fernie JM, Chapman JS, Collings P, Davis JMG. Comparison of radiographic appearances with associated pathology and lung dust content in a group of coalworkers. Br J Ind Med 1984;41:459-67.

21 Anonymous. Seronegative polyarthritis [editorial]. Br Med J 1981;283:628. 